\title{
The High Prevalence of Negative Hepatitis B Surface Antibody (Anti-HBs) among Pregnant Women in Bandung, Indonesia: A Community-Based Study
}

\author{
Dolvy Girawan, ${ }^{1,2}$ Raden T. D. Judistiani $\mathbb{D}^{2,3}$ Nelly A. Risan, ${ }^{4}$ Muhammad B. Bestari, ${ }^{1,2}$ \\ Eka S. Nugraha $\mathbb{}^{10},{ }^{1,2}$ Yudith S. Ermaya, ${ }^{2,4}$ and Dwi Prasetyo ${ }^{2,4}$ \\ ${ }^{1}$ Division of Gastroenterology and Hepatology, Department of Internal Medicine, Faculty of Medicine, Universitas Padjadjaran, \\ Dr. Hasan Sadikin General Hospital, Bandung 40161, Indonesia \\ ${ }^{2}$ Centre of Immunology Studies, Faculty of Medicine, Universitas Padjadjaran, Bandung 40161, Indonesia \\ ${ }^{3}$ Department of Public Health, Faculty of Medicine, Universitas Padjadjaran, Bandung 40161, Indonesia \\ ${ }^{4}$ Department of Child Health, Faculty of Medicine, Universitas Padjadjaran, Dr. Hasan Sadikin General Hospital, \\ Bandung 40161, Indonesia
}

Correspondence should be addressed to Eka S. Nugraha; eka.surya@unpad.ac.id

Received 30 April 2020; Accepted 12 September 2020; Published 19 October 2020

Academic Editor: Dirk Uhlmann

Copyright ( 2020 Dolvy Girawan et al. This is an open access article distributed under the Creative Commons Attribution License, which permits unrestricted use, distribution, and reproduction in any medium, provided the original work is properly cited.

Background. Hepatitis B virus (HBV) infection is a disease that creates a high global burden by affecting approximately $3.5 \%$ of the total world population. The main transmission of this disease is from mother to child (MTCT). HBV vaccination program was already initiated in Indonesia in 1987. However, after three decades, the HBV infection prevalence stays stagnant. This study aimed to explore the seroprevalence of HBV markers and the attributable risk factors of pregnant women at risk of transmitting HBV to their offspring. Method. A cross-sectional study was conducted on pregnant women from primary midwifery and obstetric clinics across Bandung, Indonesia, to assess the $\mathrm{HBsAg}$, anti-HBc, and anti-HBs serological markers. Questionnaire-based interviews were used to obtain the sociodemographic determinants. Logistic regression was applied to assess the association of each determinant factor to positive HBsAg or negative anti-HBs as a dependent variable, which was then reported as odds ratios (OR). Results. A total of 196 subjects were recruited with 12/196 (6.1\%) of them were positive HBsAg. After exclusions of those with positive HBsAg and anti-HBc, 24/175 (13.7\%) women were isolated as positive anti-HBs, leaving 151/175 (86.3\%) women with negative anti-HBs who were susceptible to HBV infection. Low body mass index (BMI) less than $18.5 \mathrm{~kg} / \mathrm{m}^{2}$ was a risk factor for positive $\mathrm{HBsAg}$ with $\mathrm{OR}=5.850$ (95\% CI 1.466-23.34), $p=0.012$. Nevertheless, no significant determinant factor was associated with negative anti-HBs. Conclusion. Most pregnant women in Bandung, Indonesia, are susceptible to HBV infection, as marked by the negative anti-HBs status.

\section{Introduction}

It is estimated that 257 million people, or $3.5 \%$ of the world population, are living with chronic HBV (hepatitis B virus) infection. The African and Western Pacific account for $68 \%$ of HBV infection [1]. Untreated HBV infection leads to cirrhosis and hepatocellular carcinoma as a life-threatening complication, responsible for approximately $96 \%$ of hepatitis-related deaths $[1,2]$. Indonesia ranks second after
India in terms of the country with the highest number of $\mathrm{HBV}$ infections in the Asia Pacific region, contributing up to $74 \%$ of deaths caused by liver cancer globally [3]. An Indonesian nationwide survey in 2013, the 2013 Indonesian Basic Health Research (IBHR), has reported an HBsAg prevalence of $7.1 \%$. Therefore, the Indonesian HBV infection endemicity is at a moderate level. However, considering the country's total population size of nearly 250 million people, the absolute number of HBV-infected individuals is high [4]. 
Various attempts have been made to fight HBV infections, including the mass $\mathrm{HBV}$ vaccination program for newborns, which dated back from a pilot project in 1987 in Lombok, West Nusa Tenggara Province, followed by the national program of hepatitis $B$ vaccination for all newborns in 1997 and training of health care providers in rural areas. It seems that the progress and accomplishments of HBV control in Indonesia are promising [5]. However, the data in 2013 IBHR presented a surprising fact that the positive HBsAg prevalence among children under five years old was still around 4.2\% [6]. Mother to child transmission (MTCT) is reported as the leading cause of HBV infections, although horizontal transmission during the early childhood period might also be the possible cause $[1,2]$.

Muljono stated that the positive HBsAg prevalence among 69,891 pregnant women across 12 provinces in Indonesia was $2.76 \%$ in 2015, with the lowest found in West Sumatra Province (1.6\%) and the highest in West Papua Province $(8.0 \%)$ [7]. These facts indicated that upscaled prevention efforts and more research are needed to stop the transmission by eliminating its causes and to achieve the national HBV elimination target.

The high HBV infection prevalence and low HBV vaccination coverage in Indonesia might be due to the unmet need of vaccination caused by challenges in vaccine supply on the community level, limited transport capacity, and inadequate cold chain capacity. Poor communication among health care professionals regarding who is responsible for HBV prevention and treatment also contributes to this matter [5].

The Government of Indonesia has issued a Decree of the Minister of Health in 2017, which sets a commitment to triple elimination of hepatitis, syphilis, and HIV infection by 2030. The government has implemented a program to screen $\mathrm{HBV}$ infections among pregnant women through HBsAg rapid test program [8]. Nonetheless, this screening approach has a drawback in those women who suffer from occult chronic HBV infection or mutant $\mathrm{HBV}$ infection could be missed. Consequently, these pregnant women become the potential source for $\mathrm{HBV}$ infection transmission to their offspring [9].

So far, no protocols have been developed for anti-HBs testing at any time after the completion of $\mathrm{HBV}$ vaccination during childhood and beyond. The assessment of chronic HBV infection and HBV serological status among women in the preconceptional period is actually the best approach to achieve the goal for HBV infection elimination, albeit more expensive [8].

Based on those facts, the Centre of Immunology Studies, Faculty of Medicine, Universitas Padjadjaran, has conducted a study to explore the seroprevalence of $\mathrm{HBV}$ markers, including $\mathrm{HBsAg}$, anti-HBc, and anti-HBs, among pregnant women in the community of Bandung city to represent Indonesia. This study emphasized the relation between baseline characteristics, socioeconomic determinants, and anti-HBs status as a long-term evaluation of vaccination coverage. Consequently, the results will provide crucial information to improve the HBV elimination programs among women in child-bearing age in Indonesia.

\section{Materials and Methods}

2.1. Study Design. This is a cross-sectional study on pregnant women in the community of Bandung, Indonesia. Questionnaire-based interviews were performed, and blood samples were collected at the same time as the interview by trained research assistants and laboratory technicians.

2.2. Study Population and Participant Recruitment. This study was conducted from July 2018 to April 2019 in 27 midwifery clinics and one private obstetric clinic in Bandung. The inclusion criteria were women with singleton near-term pregnancy (35 weeks and/or above) who resided in Bandung as proven by the identity card. The women were given complete information regarding the study objectives, procedures, and all phases of this study during their antenatal care visits or at admission for parturition. The participation in the study was voluntary, and all participants were free to withdraw from the study anytime.

2.3. Data Collection Procedure. Data on demographic characteristics and other socioeconomic determinants were obtained through interviews. Approximately $10 \mathrm{ml}$ of blood was sampled from the women's middle cubital vein for complete blood count (CBC) and $\mathrm{HBV}$ serological marker (HBsAg, anti-HBs, and anti-HBc) examinations. The remaining serum was stored for other laboratory examinations as clinically indicated or further research purposes. HBV serological markers reported in this article were based on the results of ELISA tests using Siemens ADVIA Centaur ${ }^{\circledR}$ XP immunoassay system, Erlangen, Germany.

2.4. Variables. The outcomes were set as a binary variable of HBsAg. The outcome was defined as "positive" if the participant was tested as positive for HBsAg and "negative" if the participant was tested negative for HBsAg. The same definition was also applied to the outcomes of anti-HBc and anti-HBs. The independent variables used in this study were sociodemographic characteristics that included age, weight, height, body mass index (BMI), maternal and spouse employment, cumulative monthly income, maternal education, HBV and tetanus toxoid vaccine history, obstetric history, insurance, ethnicity, and various possible routes for HBV infection such as surgery, tattoo, blood transfusion, injecting drugs, family history of $\mathrm{HBV}$, and previous personal HBV infection history.

2.5. Statistical Methods and Data Analysis. Data were analyzed using the Statistical Package for the Social Sciences (SPSS) version 24. The descriptive summary of the HBV serological marker results, i.e., the $\mathrm{HBsAg}$, anti-HBc, and anti-HBs, is presented in Table 1. The outcomes of positive HBsAg and negative anti-HBs were analyzed in relation to the independent variables. Logistic regression was applied to explore the risk factors associated with the results, then reported as the odds ratio (OR) with $95 \%$ confidence interval (CI). We considered $p<0.05$ as significant.

2.6. Ethics. Ethical approval was issued by the Health Research Ethical Committee of the Faculty of Medicine, 
TABle 1: Participant characteristics and HBsAg status.

\begin{tabular}{|c|c|c|c|c|c|}
\hline & All participants & HBsAg positive & HBsAg negative & OR (95\% CI) & $p$ \\
\hline Overall, $n(\%)$ & $196(100)$ & $12(6.1)$ & $184(93.9)$ & & \\
\hline \multicolumn{6}{|l|}{ Age } \\
\hline Mean year (SD) & $27.7(6.1)$ & $27.1(5.2)$ & $27.7(6.2)$ & & \\
\hline \multicolumn{6}{|l|}{ Distribution, $n(\%)$} \\
\hline $13-20$ & $10(5.1)$ & $1(0.5)$ & $9(4.6)$ & 1 & \\
\hline $20-24$ & $51(26.0)$ & $2(1.0)$ & $49(25.0)$ & $2.722(0.223-33.27)$ & 0.433 \\
\hline $25-29$ & $59(30.1)$ & $5(2.6)$ & $54(27.6)$ & $1.200(0.125-11.50)$ & 0.874 \\
\hline $30-34$ & $44(22.4)$ & $3(1.5)$ & $41(20.9)$ & $1.519(0.141-16.32)$ & 0.730 \\
\hline$>35$ & $32(16.3)$ & $1(0.5)$ & $31(15.8)$ & $3.444(0.195-60.71)$ & 0.398 \\
\hline \multicolumn{6}{|l|}{ Bodyweight } \\
\hline Mean kg (SD) & $53.6(9.7)$ & $56.3(8.9)$ & $53.4(9.8)$ & & \\
\hline \multicolumn{6}{|l|}{ Height } \\
\hline Median cm (IQR) & $155.0(6.0)$ & $158.0(9.0)$ & $155.0(6.0)$ & & \\
\hline \multicolumn{6}{|l|}{ BMI } \\
\hline Mean kg/m² (SD) & $22.3(3.9)$ & $23.1(3.7)$ & $22.3(3.9)$ & & \\
\hline \multicolumn{6}{|l|}{ Distribution, $n(\%)$} \\
\hline$<18.5$ & $30(15.3)$ & $5(2.6)$ & $25(12.8)$ & 1 & \\
\hline $18.5-24.9$ & $121(61.8)$ & $4(2.0)$ & $117(59.7)$ & $5.850(1.466-23.34)$ & $0.012^{\S}$ \\
\hline $25-29.9$ & $34(17.3)$ & $3(1.5)$ & $31(15.8)$ & $2.067(0.450-9.499)$ & 0.351 \\
\hline$\geq 30$ & $11(5.6)$ & $0(0)$ & $11(5.6)$ & N/A & \\
\hline \multicolumn{6}{|c|}{ Maternal employment, $n(\%)$} \\
\hline Unemployed & $143(73.0)$ & $10(5.1)$ & $133(67.9)$ & 1 & \\
\hline Fulltime & $26(13.3)$ & $1(0.5)$ & $25(12.8)$ & $1.880(0.230-15.34)$ & 0.556 \\
\hline Part time & $27(13.8)$ & $1(0.5)$ & $26(13.3)$ & $1.955(0.240-15.93)$ & 0.531 \\
\hline \multicolumn{6}{|c|}{ Spouse employment, $n(\%)$} \\
\hline Unemployed & $5(2.6)$ & $0(0)$ & $5(2.6)$ & N/A & \\
\hline Fulltime & $91(46.4)$ & $6(3.1)$ & $85(43.4)$ & 1 & \\
\hline Part time & $100(51.0)$ & $6(3.1)$ & $94(48.0)$ & $1.106(0.344-3.560)$ & 0.866 \\
\hline \multicolumn{6}{|c|}{ Family income (monthly) ${ }^{*}, n(\%)$} \\
\hline$<250$ USD & $120(61.2)$ & $8(4.1)$ & $112(57.1)$ & 1 & \\
\hline 250-499 USD & $59(30.2)$ & $4(2.0)$ & $55(28.1)$ & $0.982(0.283-3.404)$ & 0.977 \\
\hline 500-999 USD & $14(7.1)$ & $0(0)$ & $14(7.1)$ & N/A & \\
\hline$>1000$ USD & $3(1.5)$ & $0(0)$ & $3(1.5)$ & $\mathrm{N} / \mathrm{A}$ & \\
\hline \multicolumn{6}{|l|}{ Education, $n(\%)$} \\
\hline Preschool & $1(0.5)$ & $0(0)$ & $1(0.5)$ & $\mathrm{N} / \mathrm{A}$ & \\
\hline Elementary school & $8(4.1)$ & $1(0.5)$ & $7(3.6)$ & 1 & \\
\hline Intermediate school & $23(11.7)$ & $3(1.5)$ & $20(10.2)$ & $0.952(0.085-10.72)$ & 0.968 \\
\hline High school & $98(50.0)$ & $5(2.6)$ & $93(47.4)$ & $2.657(0.272-25.98)$ & 0.401 \\
\hline Graduate & $64(32.7)$ & $3(1.5)$ & $61(31.1)$ & $2.905(0.265-31.84)$ & 0.383 \\
\hline Postgraduate & $2(1.0)$ & $0(0)$ & $2(1.0)$ & N/A & \\
\hline \multicolumn{6}{|c|}{ HBV vaccine frequency history, $n(\%)$} \\
\hline Unknown & $85(43.4)$ & $5(2.6)$ & $80(40.8)$ & 1 & \\
\hline None & $108(55.1)$ & $7(3.6)$ & $101(51.5)$ & $0.902(0.276-2.948)$ & 0.864 \\
\hline $1-3$ & $2(1.0)$ & $0(0)$ & $2(1.0)$ & N/A & \\
\hline 4 & $1(0.5)$ & $0(0)$ & $1(0.5)$ & N/A & \\
\hline \multicolumn{6}{|c|}{ TT vaccine frequency history, $n(\%)$} \\
\hline None & $85(43.4)$ & $5(2.6)$ & $80(40.8)$ & 1 & \\
\hline $1-2$ & $92(46.9)$ & $6(3.1)$ & $86(43.9)$ & $0.788(0.218-2.840)$ & 0.715 \\
\hline$\geq 3$ & $19(9.7)$ & $1(0.5)$ & $18(9.2)$ & $0.563(0.059-5.363)$ & 0.617 \\
\hline
\end{tabular}


TABLE 1: Continued.

\begin{tabular}{|c|c|c|c|c|c|}
\hline & All participants & HBsAg positive & HBsAg negative & OR (95\% CI) & $p$ \\
\hline \multicolumn{6}{|l|}{ Gravidae, $n(\%)$} \\
\hline 1 & $72(36.7)$ & $5(2.6)$ & $67(34.2)$ & 1 & \\
\hline $2-3$ & $100(51.0)$ & $7(3.6)$ & $93(47.4)$ & $0.991(0.302-3.259)$ & 0.989 \\
\hline$\geq 4$ & $24(12.2)$ & $0(0)$ & $24(12.2)$ & N/A & \\
\hline \multicolumn{6}{|l|}{ Parturien, $n(\%)$} \\
\hline 0 & $77(39.2)$ & $5(2.6)$ & $72(36.7)$ & 1 & \\
\hline $1-2$ & $103(52.6)$ & $7(3.6)$ & $96(49.0)$ & $0.952(0.290-3.123)$ & 0.936 \\
\hline$\geq 3$ & $16(8.2)$ & $0(0)$ & $16(8.2)$ & N/A & \\
\hline \multicolumn{6}{|l|}{ Abortus, $n(\%)$} \\
\hline 0 & $165(84.2)$ & $11(5.6)$ & $154(78.6)$ & 1 & \\
\hline $1-2$ & $30(15.3)$ & $1(0.5)$ & $29(14.8)$ & $2.071(0.257-16.67)$ & 0.494 \\
\hline$\geq 3$ & $1(0.5)$ & $0(0)$ & $1(0.5)$ & N/A & \\
\hline \multicolumn{6}{|l|}{ Insurance, $n(\%)$} \\
\hline BPJS** & $53(27.0)$ & $2(1.0)$ & $133(67.9)$ & 1 & \\
\hline None & $143(73.0)$ & $10(5.1)$ & $51(26.0)$ & $1.917(0.406-9.052)$ & 0.411 \\
\hline \multicolumn{6}{|l|}{ Maternal ethnicity, $n(\%)$} \\
\hline Sundanese & $184(93.9)$ & $12(6.1)$ & $172(87.8)$ & N/A & \\
\hline Javanese & $8(4.1)$ & $0(0)$ & $8(4.1)$ & & \\
\hline Batak & $1(0.5)$ & $0(0)$ & $1(0.5)$ & & \\
\hline Malay & $1(0.5)$ & $0(0)$ & $1(0.5)$ & & \\
\hline Others & $2(1.0)$ & $0(0)$ & $2(1.0)$ & & \\
\hline \multicolumn{6}{|c|}{ Possible route of HBV infection, yes answered, $n(\%)$} \\
\hline Ever had hepatitis history & $0(0)$ & $0(0)$ & $0(0)$ & N/A & \\
\hline Ever had surgery & $6(3.1)$ & $0(0)$ & $6(3.1)$ & & \\
\hline Mother's tattoo & $2(1.0)$ & $0(0)$ & $2(1.0)$ & & \\
\hline Spouse's tattoo & $3(1.5)$ & $0(0)$ & $3(1.5)$ & & \\
\hline Ever had a blood transfusion & $2(1.0)$ & $0(0)$ & $2(1.0)$ & & \\
\hline Spouse's blood transfusion history & $0(0)$ & $0(0)$ & $0(0)$ & & \\
\hline Hepatitis history from a spouse & $1(0.5)$ & $0(0)$ & $1(0.5)$ & & \\
\hline Hepatitis history from family*** & $1(0.5)$ & $0(0)$ & $1(0.5)$ & & \\
\hline Mother history of IDU & $0(0)$ & $0(0)$ & $0(0)$ & & \\
\hline Spouse history of IDU & $0(0)$ & $0(0)$ & $0(0)$ & & \\
\hline
\end{tabular}

${ }^{\$}$ Significant value. ${ }^{*}$ Cumulative income rounded and converted from Indonesia Rupiah (IDR) to US Dollar (USD), ${ }^{* *}$ BPJS = Indonesian National Insurance, ${ }^{* * *}$ Mother (first ascend) or siblings. OR: odds ratio; CI: confidence interval, N/A: not applicable; TT: tetanus toxoid; IDU: injecting drug user.

Universitas Padjadjaran. All study subjects had given written informed consent to participate. Consent for publication of the study result without disclosing personal identity was also obtained.

\section{Results}

Participants' baseline characteristics, sociodemographic determinants, and positive or negative HBsAg results are listed in Table 1. The mean age of participants was 27.7 years (SD 6.1), with the majority were in the 25-29 years old group (30.1\%). Among these pregnant women, 6.1\% were HBsAg positive. Most participants were unemployed (73.0\%), and half of the spouses had a part-time job (51.0\%) with a cumulative monthly income of less than 250 USD (61.2\%). Almost all participants (98.5\%) in both positive HBsAg and negative
HBsAg groups did not recall having $\mathrm{HBV}$ vaccination in the past. Among all determinants, only being underweight was associated with having positive $\mathrm{HBsAg}(\mathrm{OR}=5.850$ with 95\% CI 1.466-23.34, $p=0.012$ ).

Table 2 shows the combination results of HBV serological markers of all participants and their interpretation, which are classified into eight groups. Subjects with positive HBsAg, positive anti-HBc, but negative anti-HBs accounted for $1.5 \%$ of this study population. Meanwhile, only $4.6 \%$ had isolated positive HBsAg. However, the triple-negative serological marker finding was predominant in this study (77.0\%), while isolated positive anti-HBs accounted for $12.3 \%$ of the study population.

Further analyses on the association of baseline and socioeconomic determinants and negative anti-HBs are displayed in Table 3. After the exclusion of positive HBsAg and/or anti- 
TABLe 2: Hepatitis B infection serological markers.

\begin{tabular}{lccccc}
\hline HBsAg & Anti-HBc & Anti-HBs & All, $n(\%)$ & Born before 1990, $n(\%)$ & Born after 1990, $n(\%)$ \\
\hline+ & + & + & $0(0)$ & $0(0)$ & $0(0)$ \\
+ & + & - & $3(1.5)$ & $1(0.5)$ & $2(1.0)$ \\
+ & - & + & $0(0)$ & $0(0)$ & $0(0)$ \\
+ & - & - & $9(4.6)$ & $3(1.5)$ & $6(3.0)$ \\
- & + & + & $6(3.1)$ & $4(2.0)$ & $2(1.0)$ \\
- & + & - & $3(1.5)$ & $3(1.5)$ & $0(0)$ \\
- & - & + & $24(12.3)$ & $12(6.1)$ & $12(6.1)$ \\
- & - & - & $151(77.0)$ & $69(35.2)$ & $82(41.8)$ \\
Total & & & $196(100)$ & $92(46.9)$ & $104(53.1)$ \\
\hline
\end{tabular}

$\mathrm{HBc}$, a total of 175 of 196 subjects were included. Bivariate analysis revealed none of the determinants had significant associations with the negative anti-HBs result.

\section{Discussions}

This was the first seroprevalence study of $\mathrm{HBsAg}$, anti-HBc, and anti-HBs status among pregnant women in Bandung, Indonesia, that aimed at assessing the risk for $\mathrm{HBV}$ mother to child transmission (MTCT). The overall prevalence of HBsAg positive was $6.1 \%$ in the screened population. This prevalence is comparable to the prevalence among pregnant women in Makassar, Indonesia, which is 6.8\% [10]. Despite several wide-scale vaccination campaigns that have been held since 1985, these findings indicate that the Indonesian HBV prevalence remains in the intermediate group according to the WHO criteria, as the prevalence is between 2 and $8 \%$ [11]. Other neigbouring Southeast Asian countries also present an HBV infection prevalence that ranges from moderate $(2-8 \%)$, such as in Thailand (3\%), to high $(>8 \%)$, such as the Philippines (16\%) [3].

This study revealed that approximately $78.5 \%$ of these women were between 20 and 34 years old. Nearly all participants in the positive HBsAg group had at least one or more children, with half of them might be very likely to have another pregnancy some time in the future. Around $61.2 \%$ of women came from a low-income family (less than 250 USD per month), which might be a constraint for getting $\mathrm{HBV}$ vaccination although the majority of these women $(83.7 \%)$ had completed senior high school.

Routine HBV screening during pregnancy using the maternal HBsAg test has been suggested by the Society for Maternal-Fetal Medicine [12]. New evidence from Indonesia has proven that the HBsAg level provides an excellent viral load predictor in HBeAg-positive pregnant women, but not in $\mathrm{HBeAg-negative} \mathrm{pregnant} \mathrm{women} \mathrm{[10].} \mathrm{Cautions} \mathrm{should}$ be applied when assessing pregnant women who are in the immune-tolerant phase of chronic HBV infection with high-level viremia but with typical physical or laboratory results. This would, unfortunately, lead to the lack of awareness of their HBsAg-positive status and increase the risk of transmitting the HBV virus to their offspring [10].

A small number of pregnant women in this study had personal or familial behaviour risk factors for $\mathrm{HBV}$ infection.
Still, those risk factors seem to be unrelated to HBV infection, as marked by positive HBsAg. Almost all of the women (98.5\%) did not recall having HBV vaccination. In comparison, women who did not remember the tetanus toxoid (TT) vaccination was only $43.4 \%$ in accordance with Table 1 ). This might not indicate the real condition, and reconfirmation was not feasible due to poor personal records.

Table 2 shows that twelve women $(6.1 \%)$ were positive HBsAg. Three other women (1.5\%) had a combination of positive anti-HBc and negative $\mathrm{HBsAg}$ and anti-HBs, reflecting the possibility that they might have occult HBV infections. Further assessment is needed to confirm the diagnosis of HBV among these women. The health impact of $\mathrm{HBV}$ infection increases over time as individuals with chronic infection age and develop HBV-related complications. Up to $40 \%$ of individuals with chronic HBV infection progress to cirrhosis, liver failure, and hepatocellular carcinoma [13].

As presented in Table 3, a large proportion of subjects (172 of 175 subjects, $98.3 \%$ ) might not have any HBV vaccination in the past or do not recall past HBV vaccination. This fact is in contrast with the previous report stating that the average $\mathrm{HBV}$ vaccination coverage in West Java Province, including Bandung, is as high as $80 \%$ [6]. The findings of this study demonstrate that only $24(12.3 \%)$ women had positive anti-HBs, while 151 (77.0\%) were negative anti-HBs. Those women with negative anti-HBs were at-risk or susceptible to $\mathrm{HBV}$ infection. Therefore, keeping good vaccination records of every pregnant woman and newborn should be further encouraged. The recorded data should contain information on the type of vaccine used and the time of administration. The Ministry of Health has actually provided a book for mother and child health record known as "Buku Kesehatan Ibu dan Anak" or "Buku KIA" to be used to record data on individual mother and child. This book provides spaces for recording vaccination and is distributed for free and routinely used in primary health centres. It should be encouraged that this book should be kept as an important documentation for life.

This study has identified various baseline characteristics and socioeconomic factors that may be associated with the negative anti-HBs result (see Table 3 ). Identification of risk factors is essential to inform the stakeholders of the HBV prevention program. Although the statistical analysis of the 
TABLE 3: Analyses of anti-HBs-negative subjects after excluding HBsAg- and Anti-HBc-positive subjects.

\begin{tabular}{|c|c|c|c|c|}
\hline & Frequency & Negative anti-HBs & OR $(95 \% \mathrm{CI})$ & $p$ \\
\hline Overall, $n(\%)$ & $175(100)$ & $151(86.3)$ & & \\
\hline \multicolumn{5}{|l|}{ Age distribution, $n(\%)$} \\
\hline $13-20$ & $9(5.1)$ & $7(4.0)$ & 1 & \\
\hline $20-24$ & $49(28.0)$ & $44(25.1)$ & $0.398(0.064-2.463)$ & 0.322 \\
\hline $25-29$ & $51(29.1)$ & $45(25.7)$ & $0.467(0.078-2.788)$ & 0.403 \\
\hline $30-34$ & $35(20.0)$ & $30(17.1)$ & $0.583(0.093-3.653)$ & 0.565 \\
\hline$>35$ & $31(17.7)$ & $25(14.3)$ & $0.840(0.138-5.115)$ & 0.850 \\
\hline \multicolumn{5}{|l|}{ BMI distribution, $n(\%)$} \\
\hline$<18.5$ & $25(14.3)$ & $21(12.0)$ & 1 & \\
\hline $18.5-24.9$ & $110(62.9)$ & $96(54.9)$ & $0.766(0.229-2.561)$ & 0.665 \\
\hline $25-29.9$ & $30(17.1)$ & $26(14.9)$ & $0.808(0.180-3.622)$ & 0.780 \\
\hline$\geq 30$ & $10(5.7)$ & $8(4.6)$ & $1.312(0.200-8.624)$ & 0.777 \\
\hline \multicolumn{5}{|c|}{ Maternal employment, $n(\%)$} \\
\hline Unemployed & $128(73.1)$ & $114(65.1)$ & 1 & \\
\hline Fulltime & $24(13.7)$ & $19(10.9)$ & $2.143(0.692-6.638)$ & 0.186 \\
\hline Part time & $23(13.1)$ & $18(10.3)$ & $2.262(0.727-7.042)$ & 0.159 \\
\hline \multicolumn{5}{|c|}{ Spouse employment, $n(\%)$} \\
\hline Unemployed & $5(2.9)$ & $3(1.7)$ & 1 & \\
\hline Fulltime & $82(46.9)$ & $70(40.0)$ & $0.257(0.039-1.704)$ & 0.257 \\
\hline Part time & $88(50.3)$ & $78(44.6)$ & $0.192(0.029-1.294)$ & 0.192 \\
\hline \multicolumn{5}{|c|}{ Family income (monthly) ${ }^{*}, n(\%)$} \\
\hline$<250$ USD & $106(60.6)$ & $90(51.4)$ & 1 & \\
\hline 250-499 USD & $54(30.9)$ & $48(27.4)$ & $0.703(0.258-1.914)$ & 0.491 \\
\hline 500-999 USD & $12(6.9)$ & $11(6.3)$ & $0.511(0.062-4.239)$ & 0.534 \\
\hline$>1000$ USD & $3(1.7)$ & $2(1.1)$ & $2.813(0.241-32.87)$ & 0.410 \\
\hline \multicolumn{5}{|l|}{ Education, $n(\%)$} \\
\hline Preschool & $1(0.6)$ & $1(0.6)$ & N/A & \\
\hline Elementary school & $6(3.4)$ & $5(2.9)$ & 1 & \\
\hline Intermediate school & $19(10.9)$ & $16(9.1)$ & $0.938(0.079-11.15)$ & 0.959 \\
\hline High school & $90(51.4)$ & $77(44.0)$ & $0.844(0.091-7.819)$ & 0.881 \\
\hline Graduate & $57(32.6)$ & $51(29.1)$ & $0.588(0.059-5.912)$ & 0.652 \\
\hline Postgraduate & $2(1.1)$ & $1(0.6)$ & $5.0(0.150-166.6)$ & 0.368 \\
\hline \multicolumn{5}{|c|}{ HBV vaccine frequency history, $n(\%)$} \\
\hline Unknown & $75(42.9)$ & $61(34.9)$ & 1 & \\
\hline None & $97(55.4)$ & $87(49.7)$ & $1.997(0.832-4.780)$ & 0.121 \\
\hline $1-3$ & $2(1.1)$ & $2(1.1)$ & N/A & \\
\hline 4 & $1(0.6)$ & $1(0.6)$ & N/A & \\
\hline \multicolumn{5}{|l|}{ Insurance, $n(\%)$} \\
\hline BPJS** & $48(27.4)$ & $44(25.1)$ & 1 & \\
\hline None & $127(72.6)$ & $107(61.1)$ & $0.486(0.157-1.505)$ & 0.211 \\
\hline \multicolumn{5}{|l|}{ Mother ethnicity, $n(\%)$} \\
\hline Sundanese & $165(94.3)$ & $142(81.1)$ & 1 & \\
\hline Javanese & $7(4.0)$ & $6(3.4)$ & $1.029(0.118-8.944)$ & 0.979 \\
\hline Batak & $1(0.6)$ & $1(0.6)$ & N/A & \\
\hline Malay & $1(0.6)$ & $1(0.6)$ & N/A & \\
\hline Others & $1(0.6)$ & $1(0.6)$ & N/A & \\
\hline
\end{tabular}

${ }^{*}$ Cumulative income rounded and converted from Indonesia Rupiah (IDR) to US Dollar (USD), ${ }^{* *}$ BPJS = Indonesian National Insurance, OR: odds ratio; CI: confident interval; N/A: not applicable. 
independent variables against the anti-HBs status does not result in significant results in this study, there are some factors that might be associated with negative anti-HBs, including low income (less than 250 USD per month), unemployment, lack of insurance ownership, and unknown HBV or TT vaccine history. Additionally, in countries with perinatal $\mathrm{HBV}$ programs like Indonesia, all infants should receive three scheduled doses of $\mathrm{HBV}$ vaccination [5]. The vaccination at 0,1 , and 6 months should attain a positive anti-HBs value of more than $10 \mathrm{mIU} / \mathrm{mL}$ to be able to provide adequate protection against $\mathrm{HBV}$ infection $[9,14]$. It would be best to check for the seroconversion of anti-HBs in these infants.

So far, there has been no protocol available on HBV booster vaccination for women in reproductive age. The real challenge is reflected from 151 of 175 (86.3\%) women who are susceptible to $\mathrm{HBV}$ infection because of their negative $\mathrm{HBsAg}$, anti-HBc, and anti-HBs status (see Table 2). Two possible explanations are they never have HBV vaccination before and they might be in the nonresponder group [9].

$\mathrm{HBV}$ vaccination is indicated in adults who are prone to acquiring $\mathrm{HBV}$ infection from frequent exposure to $\mathrm{HBV}$ infected individuals. Vaccination against HBV during pregnancy is safe, and the immunogenicity would be efficient for the passive transfer of maternal antibody to newborns. No significant adverse reaction has been reported in HBVvaccinated pregnant women as compared to those without vaccination [14].

Recommendations have been made on emergency HBV immunization in high-risk pregnant populations. HBV vaccination, with or without HBV immunoglobulin, is recommended for postexposure prophylaxis to prevent $\mathrm{HBV}$ infection. High risk is defined as having a sex partner with positive HBsAg, promiscuity, presence of sexually transmitted disease, and injecting drug behaviour [14].

In practice, the $\mathrm{HBV}$ vaccine can be administered to women in 3 doses over a period of 6 months before, during, and after pregnancy, despite that FDA classifies $\mathrm{HBV}$ vaccine as a C-level drug for pregnant women. No conclusion on the advisability of HBV vaccination among pregnant women population could be drawn from the Global Advisory Committee on Vaccine Safety, and the rarity of evidence of $\mathrm{HBV}$ vaccination in pregnant women would be a real challenge for its application $[15,16]$.

This study reported a low anti-HBs positive rate in pregnant women $(12.3 \%)$. This should raise an awareness that the HBV vaccination should be extended to women of childbearing age. The World Health Organization (WHO) called for the elimination of $\mathrm{HBV}$ infection as a public health threat by 2030 and to reduce new chronic infections by $90 \%$ and mortality by $65 \%$ in 2020 . The prevention of vertical transmission from mother-to-child and prevention of infant and childhood infection are a cornerstone of the global strategy and recommended for all countries regardless of their HBV endemicity [2]. The best practice would be HBV vaccination at birth and early infancy. A mathematical model has demonstrated that an $\mathrm{HBV}$ vaccine coverage of $90 \%$ will prevent $84 \%$ of HBV-related deaths worldwide [2].
Pregnant women are considered immunocompromised individuals who experience a decrease in antibody titers [17]. An administration of additional vaccine booster before pregnancy may be suggested. HBV vaccine booster triggers the increase in protective antibody levels for 10 to 30 years [9]. Further studies are needed to solve the problem in nonresponder individuals and also to prove the safety and efficacy of HBV vaccination in pregnant women with negative anti-HBs.

\section{Conclusions}

This study shows that most pregnant women in Bandung, Indonesia, are negative anti-HBs. Therefore, they are not protected from hepatitis B infection. Based on these findings, it is recommended that $\mathrm{HBV}$ vaccination is provided to all pregnant women.

\section{Data Availability}

The datasets generated during and/or analysed during the current study are available from the corresponding author on reasonable request. Correspondence or request should be addressed to the Division of Gastroenterology and Hepatology, Department of Internal Medicine Hasan Sadikin General Hospital, Universitas Padjadjaran. Address: Jalan Pasteur 38 Bandung, 40161, Indonesia. E-mail: eka.surya@unpad.ac.id.

\section{Conflicts of Interest}

All authors declared having no conflict of interest.

\section{Authors' Contributions}

DG and RTDJ shared equal contributions throughout the research process, discussion, and manuscript writing. ESN and RTDJ performed data analysis and manuscript writing. MBB designed the research and wrote the grant proposal. NAR, YSE, and DP were involved in research design, grant proposal writing, discussion of the study result, and revision of the final draft.

\section{Acknowledgments}

We express our gratitude for the cooperation and hard works of all midwives and obstetric practitioners for their participation in this study. We thank our research assistant, Ms. Susani, and all laboratory technicians at the Immunology Unit of the Clinical Pathology Department, Faculty of Medicine, Universitas Padjadjaran, for their dedication to this study. This study was supported by the Academic Leadership Grants (ALG) Universitas Padjadjaran year 2018-2019 awarded to Professor Dwi Prasetyo, MD, PhD (pediatric consultant).

\section{References}

[1] World Health Organization, "Global Hepatitis Programme. Global hepatitis report,” 2017. 
[2] World Health Organization Regional Office for the Western Pacific, Expert Consultation on Triple Elimination of Motherto-Child Transmission of HIV, Hepatitis B and Syphilis in the Western Pacific, WHO, Manila, Philippines, 2017.

[3] S. Wait, E. Kell, S. Hamid et al., "Hepatitis B and hepatitis C in Southeast and Southern Asia: challenges for governments," The Lancet Gastroenterology \& Hepatology, vol. 1, no. 3, pp. 248-255, 2016.

[4] D. Muljono, "Epidemiology of hepatitis B and C in Republic of Indonesia," Euroasian journal of hepato-gastroenterology, vol. 7, no. 1, pp. 55-59, 2017.

[5] M. Creati, A. Saleh, T. A. Ruff et al., "Implementing the birth dose of hepatitis B vaccine in rural Indonesia," Vaccine, vol. 25, no. 32, pp. 5985-5993, 2007.

[6] Badan Penelitian dan Pengembangan Kesehatan, "Basic Health Research 2013," in Riset Kesehatan Dasar 2013, Ministry of Health Republic of Indonesia, Jakarta, Indonesia, 2013.

[7] D. H. Muljono, From Epidemiological and Scientific Findings to Clinical and Public Health Impact: Hepatitis B as a Model, University of Hasanudin, Makasar, Indonesia, 2018.

[8] "Regulation of the minister of health number 52, 2017, the elimination of mother to child transmission of human immunodeficiency virus, syphilis, and hepatitis," in Peraturan Menteri Kesehatan Republik Indonesia Nomor 52 Tahun 2017 Tentang Eliminasi Penularan Human Immunodeficiency Virus, Sifilis dan Hepatitis dari Ibu ke Anakp. 2013.

[9] S. Walayat, Z. Ahmed, D. Martin, S. Puli, M. Cashman, and S. Dhillon, "Recent advances in vaccination of nonresponders to standard dose hepatitis B virus vaccine," World journal of hepatology, vol. 7, no. 24, pp. 2503-2509, 2015.

[10] M. Fujiko, M. T. Chalid, Turyadi et al., "Chronic hepatitis B in pregnant women: is hepatitis B surface antigen quantification useful for viral load prediction?," International Journal of Infectious Diseases, vol. 41, pp. 83-89, 2015.

[11] J. Hou, Z. Liu, and F. Gu, "Epidemiology and prevention of hepatitis B virus infection," International Journal of Medical Sciences, vol. 2, no. 1, pp. 50-57, 2005.

[12] Society for Maternal-Fetal Medicine (SMFM), J. DionneOdom, A. T. Tita, and N. S. Silverman, “\#38: Hepatitis B in pregnancy screening, treatment, and prevention of vertical transmission," American journal of obstetrics and gynecology, vol. 214, no. 1, pp. 6-14, 2016.

[13] R. G. Gish, B. D. Given, C.-L. Lai et al., "Chronic hepatitis B: virology, natural history, current management and a glimpse at future opportunities," Antiviral Research, vol. 121, pp. 4758,2015

[14] Y. Zhao, H. Jin, X. Zhang, B. Wang, and P. Liu, "Viral hepatitis vaccination during pregnancy," Human Vaccines \& Immunotherapeutics, vol. 12, no. 4, pp. 894-902, 2016.

[15] Y.-C. Chien, C.-F. Jan, H.-S. Kuo, and C.-J. Chen, "Nationwide hepatitis B vaccination program in Taiwan: effectiveness in the 20 years after it was launched," Epidemiologic Reviews, vol. 28, no. 1, pp. 126-135, 2006.

[16] M. S. Chang and M. H. Nguyen, "Epidemiology of hepatitis B and the role of vaccination," Best Practice \& Research. Clinical Gastroenterology, vol. 31, no. 3, pp. 239-247, 2017.

[17] M. M. Jonas, "Hepatitis B and pregnancy: an underestimated issue," Liver international, vol. 29, no. s1, pp. 133-139, 2009. 